\title{
PENJADWALAN PERAWAT IGD RUMAH SAKIT UMUM DAERAH KOTA BANDUNG MENGGUNAKAN METODE GOAL PROGRAMMING
}

\author{
Mardhiyah Herdyati ${ }^{1}$, Eman Lesmana², Julita Nahar ${ }^{3}$ \\ 1,2,3 Universitas Padjadjaran, Jln. Raya Bandung-Sumedang Km. 21 Jatinangor, Sumedang, Indonesia \\ email: mdhiyahh16@gmail.com
}

\begin{abstract}
Hospitals are community needs as a service in the health sector. People who need medical treatment can come to one part of the hospital, namely the Emergency Installation (IGD). People can need an emergency room at any time. Therefore nurses are available 24 hours a day. But a nurse cannot work full 24 hours a day in the hospital or work on the same shift two days or more in a row because it can affect the health of the nurse. This paper discusses the scheduling of nurses using the Goal Programming Method. The goal progamming method is to solve the problems of scheduling IGD nurses in the Regional General Hospital of Bandung City with the aim of minimizing deviations from the objective function. The method in this study is adjusted to the policies that apply in the hospital and the needs of nurses. The results of this study can minimize deviations so that the optimal nurse schedule is obtained.
\end{abstract}

Keywords : Nurses Scheduling, Emergency Installation, Goal Programming Method

\begin{abstract}
ABSTRAK
Rumah sakit merupakan kebutuhan masyarakat sebagai pelayanan dibidang kesehatan. Masyarakat yang membutuhkan penanganan medis dapat datang ke salah satu bagian rumah sakit yaitu Instalasi Gawat Darurat (IGD). Masyarakat dapat membutuhkan IGD kapan saja. Oleh karena itu dibutuhkan perawat yang siap sedia selama 24 jam dalam satu hari. Namun seorang perawat tidak dapat bekerja penuh 24 jam dalam sehari di rumah sakit atau bekerja pada shift yang sama dua hari atau lebih berturut-turut karena dapat mempengaruhi kesehatan perawat. Makalah ini membahas tentang penjadwalan perawat menggunakan Metode Goal Programming. Metode goal progamming untuk menyelesaikan permasalahan penjadwalan perawat IGD Rumah Sakit Umum Daerah Kota Bandung dengan tujuan meminimumkan penyimpangan pada fungsi tujuan. Metode dalam penelitian ini disesuaikan dengan kebijakan-kebijakan yang berlaku di rumah sakit dan kebutuhan perawat. Hasil dari penelitian ini dapat meminimumkan penyimpangan menjadi nol, sehingga didapat jadwal perawat yang optimal.
\end{abstract}

Kata Kunci: Penjadwalan Perawat, IGD, Metode Goal Programming

Dikirim : 8 Agustus 2019; Diterima: 27 September 2019; Dipublikasikan : 30 September 2019

Cara sitasi: Herdyati, M. Lesmana, E \& Naha, J. (2019). Penjadwalan perawat IGD Rumah Sakit Umum Daerah Kota Bandung menggunakan metode goal programming. Teorema: Teori dan Riset Matematika, 4(2), 99-110. 


\section{PENDAHULUAN}

Di era globalisasi masyarakat membutuhkan rumah sakit sebagai pelayanan dibidang kesehatan. Masyarakat yang membutuhkan pelayanan kesehatan dapat datang ke rumah sakit terdekat. Untuk masyarakat yang datang ke rumah sakit karena cedera atau masalah kesehatan yang membutuhkan penanganan medis dapat datang ke salah satu bagian rumah sakit yaitu Instalasi Gawat Darurat (IGD). IGD memberikan pelayanan gawat darurat dengan cepat dan tepat sesuai dengan kebutuhan masyarakat.

Pasien yang datang ke IGD biasanya atas rujukan dokter pribadi atau rujukan puskesmas. Pasien yang datang ke IGD apabila telah selesai ditangani maka dapat pulang, dipindahkan ke ruang rawat inap atau apabila pasien meninggal di IGD maka akan dipindahkan ke kamar jenazah. Oleh karena itu masyarakat dapat membutuhkan rumah sakit kapan saja.

IGD harus siap sedia 24 jam sehari maka dibutuhkan perawat untuk melayani masyarakat yang datang. Namun perawat di IGD tidak dapat bekerja penuh 24 jam dalam sehari di rumah sakit. Maka dari itu dibutuhkan penjadwalan shift kerja perawat IGD di rumah sakit. Penjadwalan tersebut dibagi atas tiga waktu dalam sehari yaitu shift pagi, shift siang, dan shift malam. Penjadwalan tersebut dilakukan dalam periode waktu satu minggu. Seorang perawat dapat bekerja di shift yang berbeda setiap harinya, karena apabila shift kerja diwaktu yang sama dapat mempegaruhi kesehatan perawat. Contohnya perawat yang bekerja di shift malam, apabila setiap harinya ia memiliki shift kerja diwaktu yang sama dapat berdampak buruk ke kesehatannya. Dengan mempertimbangkan kendala-kendala dan kebijakan rumah sakit maka penjadwalan dapat dilakukan menggunakan Metode Goal Programming. Jaenal et al (2011) melakukan penelitian penjadwalan perawat dengan menggunakan Metode Goal Programming membuat pola siklus penjadwalan perawat sehingga dapat meringankan pekerjaan kepala perawat atau manajer perawat. Sehingga kepala perawat atau manajer perawat mengeluarkan sedikit usaha dalam membuat jadwal yang baru. Hasil yang diperoleh dari model ini memberikan solusi yang optimal dimana semua tujuan tercapai. Penelitian ini akan menerapkan Metode Goal Programming.

Maksud dari penelitian ini yaitu mengetahui bagaimana penerapan Metode Goal Programming pada penjadwalan perawat IGD Rumah Sakit Umum Daerah Kota Bandung. Tujuan dari penelitian ini yaitu memperoleh model Goal Programming pada penjadwalan perawat IGD Rumah Sakit Umum Daerah Kota Bandung.

\section{METODE PENELITIAN}

\section{Penjadwalan}

Menurut Husen (2008) penjadwalan adalah pengalokasian waktu yang tersedia untuk melaksanakan masing-masing pekerjaan dalam rangka menyelesaikan suatu kegiatan hingga tercapai hasil yang optimal dengan mempertimbangkan keterbatasan-keterbatasan yang ada.

Secara umum penjadwalan mempunyai manfaat-manfaat sebagai berikut:

1. Memberikan pedoman terhadap pekerjaan atau kegiatan mengenai batas-batas waktu untuk mulai dan akhir dari masing-masing tugas

2. Memberikan alat bagi pihak manajemen untuk mengkoordinir secara sistematis dan realistis dalam penentuan alokasi prioritas terhadap sumber daya waktu

3. Memberikan sarana untuk menilai kemajuan pekerjaan

4. Menghindari pemakaian sumber daya yang berlebihan

5. Memberikan kepastian waktu pelaksanaan pekerjaan.

\section{Goal Programming}

Menurut Hiller \& Lieberman (2001) Goal Programming adalah untuk menetapkan sasaran numerik spesifik untuk masing-masing tujuan, merumuskan fungsi tujuan untuk setiap tujuan, dan kemudian mencari solusi yang meminimalkan jumlah (bobot) penyimpangan dari fungsi-fungsi objektif ini dari tujuan masing-masing. Menurut Rao (2009) Goal Programming adalah teknik yang 
terkenal untuk memecahkan jenis multiobjektif masalah optimasi. Goal Programming awalnya diusulkan untuk masalah linier oleh Charnes \& Cooper pada tahun 1961.

Menurut Taha (1997) dalam menyelesaikan masalah Goal Programming terdapat dua algoritma untuk menyelesaikan masalah tersebut. Metode pertama yaitu weighting method, fungsi objektif tunggal dibentuk sebagai jumlah bobot dari fungsi yang mewakili masalah tujuan. Metode yang kedua yaitu preemptive method dimulai dengan memprioritaskan tujuan dalam urutan kepentingan. Permasalahan yang dioptimalkan menggunakan satu tujuan pada satu waktu, dan sedemikian rupa sehingga nilai optimal dari tujuan prioritas yang lebih tinggi tidak terdegradasi oleh tujuan prioritas yang lebih rendah. Dua metode yang diusulkan berbeda, dalam arti bahwa mereka umumnya tidak akan menghasilkan solusi yang sama. Namun dapat diklaim unggul karena setiap teknik dirancang untuk memenuhi preferensi pengambilan keputusan tertentu.

Menurut Taha (1997) misalkan model Goal Programming memiliki $n$ tujuan dan tujuan ke-i diberikan sebagai berikut:

Meminimumkan $z_{\mathrm{i}}, i=1,2, \ldots, n$ berikut:

Gabungan fungsi tujuan yang digunakan dalam weighting method didefinisikan sebagai

Meminimumkan $z=w_{1} z_{1}+w_{2} z_{2}+. .+w_{n} z_{n}$

Dimana $w_{i}, i=1,2, \ldots n$ adalah bobot positif yang mencerminkan preferensi pembuat keputusan mengenai kepentingan relatif setiap tujuan. Sebagai contoh, $w_{i}=1$, untuk semua $i$, menandakan bahwa semua sasaran memiliki bobot yang sama. Penentuan nilai spesifik dari bobot ini adalah subjektif.

Istilah-istilah yang digunakan dalam metode goal programming

1. Variabel Deviasi

Variabel deviasi merupakan variabel yang menunjukan kemungkinan penyimpangan penyimpangan negatif dan positif dari nilai ruas kanan fungsi tujuan. Variabel penyimpangan negatif berfungsi untuk menampung penyimpangan yang berada di bawah sasaran yang dikehendaki, sedangkan variabel penyimpangan positif berfungsi menampung penyimpangan yang berada di atas sasaran. Variabel deviasi dinotasikan dengan $d_{i}^{-}$untuk penyimpangan negatif dan $d_{i}^{+}$untuk penyimpangan postif.

2. Variabel Keputusan

Variabel keputusan merupakan variabel-variabel yang tidak diketahui dalam model Goal Programming yang dinotasikan dengan $x_{j}$ dimana $\mathrm{j}=1,2,3, \ldots, \mathrm{n}$ dan nilai $x_{j}$ yang akan dicari.

3. Nilai Ruas Kanan

Nilai ruas kanan atau Right Hand Side values (RHS) adalah nilai yang biasanya menunjukkan besaran ketersediaan sumber daya yang dinotasikan dengan $b_{i}$.

4. Goal

Goal merupakan tujuan dalam Goal Programming yaitu meminimumkan nilai penyimpangan dari suatu RHS pada suatu kendala tujuan tertentu.

5. Kendala

Kendala tujuan adalah suatu tujuan yang diekspresikan dalam persamaan matematika dengan memasukkan variabel simpangan.

6. Prioritas

Suatu sistem urutan yang memungkinkan tujuan-tujuan disusun secara ordinal dalam model Goal Programming

7. Bobot

Bobot dalam Goal Programming adalah timbangan matematika yang dinotasikan dengan angka kardinal (dilambangkan dengan $w_{k i}$ dimana $\mathrm{k}=1,2, \ldots, \mathrm{m}$ ) dan digunakan untuk membedakan variabel simpangan $i$ di dalam suatu tingkat prioritas $k$. Pemberian bobot dilakukan dikarenakan 
adanya pertimbangan bahwa setiap kendala memiliki tingkat kepentingan yang berbeda dalam pengoptimalannya.

8. Technological Coefficient

Nilai - nilai numerik (dinotasikan dengan $a_{i j}$ ) yang merupakan koefisien dari variabel keputusan.

\section{HASIL DAN PEMBAHASAN}

Data penelitian ini adalah data dari jadwal perawat IGD di Rumah Sakit Umum Daerah Kota Bandung pada bulan Januari. Data disajikan dalam bentuk tabel untuk mempermudah dalam proses analisis. Data yang digunakan dalam penelitian ini sebanyak 24 perawat.

\section{Penerapan Metode Goal Programming pada Penjadwalan Perawat IGD}

Pada penjadwalan perawat IGD diberikan parameter-parameter yang disajikan pada Tabel 1.

Tabel 1. Parameter pada penelitian

\begin{tabular}{ll}
\hline Parameter & Keterangan \\
\hline$m$ & Banyaknya hari yang digunakan pada penjadwalan dalam satu periode \\
& Banyaknya perawat yang bertugas di IGD \\
$n$ & Banyaknya perawat yang bertugas di IGD \\
$i$ & Indeks hari $(i=1,2, \ldots, m)$ \\
$i$ & Indeks perawat $(j=1,2, \ldots, n)$ \\
$x_{j \max }$ & Jumlah maksimum perawat yang bertugas untuk shift pagi di hari ke-i \\
$x_{j \min }$ & Jumlah minimum perawat yang bertugas untuk shift pagi di hari ke-i \\
$y_{j \max }$ & Jumlah maksimum perawat yang bertugas untuk shift siang di hari ke-i \\
$y_{j \min }$ & Jumlah minimum perawat yang bertugas untuk shift siang di hari ke-i \\
$z_{j \max }$ & Jumlah maksimum perawat yang bertugas untuk shift malam di hari \\
& ke-i \\
$z_{j \operatorname{lmin}}$ & Jumlah minimum perawat yang bertugas untuk shift malam di hari ke-i \\
$D_{\text {total }}$ & Banyaknya hari kerja yang harus dipenuhi oleh setiap perawat dalam \\
& satu periode (satu minggu) \\
\hline
\end{tabular}

\section{$1.1 \quad$ Variabel Keputusan}

$x_{i j}\left\{\begin{array}{l}1, \\ 0,\end{array}\right.$

1. jika perawat $j$ bertugas pada shift pagi di hari ke $-i$

0 , jika perawat $j$ tidak bertugas pada shift pagi di hari ke $-i$

$y_{i j} \begin{cases}1, & \text { jika perawat } j \text { bertugas pada shift siang di hari ke }-i \\ 0, & \text { jika perawat } j \text { tidak bertugas pada shift siang di hari ke }-i\end{cases}$

$z_{i j} \begin{cases}1, & \text { jika perawat } j \text { bertugas pada shift malam di hari ke }-i \\ 0, & \text { jika perawat } j \text { tidak bertugas pada shift malam di hari ke }-i\end{cases}$

$h_{i j} \begin{cases}1, & \text { jika perawat } i j l i b u r \text { di hari ke }-1 \\ 0, & \text { jika perawat } j \text { tidak libur di hari ke }-1\end{cases}$

dengan

$(i=1,2 \ldots m)$

$(j=1,2, \ldots, n)$

\subsection{Hard Constraint}

Hard Constraint merupakan batasan yang mempresentasikan peraturan/kebijakan yang tidak dapat diubah atau dilanggar. 
a. Kendala 1

Pemenuhan persyarat agar batas minimal kebutuhan perawat bekerja disetiap shift kerja terpenuhi untuk setiap $i=1,2, \ldots, m$ berlaku:

$$
\begin{aligned}
& \sum_{j=1}^{n} x_{i j} \geq x_{j \min } \\
& \sum_{j=1}^{n} y_{i j} \geq y_{j \min } \\
& \sum_{j=1}^{n} z_{i j} \geq z_{j \text { min }}
\end{aligned}
$$

b. Kendala 2

Jumlah perawat yang bekerja pada shift pagi, shift siang, shift malam dan perawat yang libur sama dengan jumlah semua perawat yang ada untuk setiap $i=1,2, \ldots, m$ berlaku:

$$
\sum_{j=1}^{n}\left(x_{i j}+y_{i j}+z_{i j}+h_{i j}\right)=n
$$

c. Kendala 3

Setiap perawat bertugas tidak bekerja lebih dari satu shift dalam satu hari. Untuk setiap $i=1,2, \ldots, m$ dan $j=1,2, \ldots, n$ berlaku:

$x_{i j}+y_{i j}+z_{i j}+h_{i j}=1$

d. Kendala 4

Jika seorang perawat sudah bertugas pada shift malam, maka perawat tersebut libur dihari berikutnya, untuk setiap $i=1,2, \ldots(m-1)$ dan $j=1,2, \ldots n$ berlaku:

$$
z_{\mathrm{i} j}+x_{(i+1) j}+y_{(i+1) j}+z_{(i+1) j} \leq 1
$$

e. Kendala 5

Setiap perawat memiliki batas maksimal dua shift kerja dalam satu periode untuk setiap $j=1,2, \ldots, n$ berlaku:

$\sum_{i=1}^{m} x_{i j} \leq 2$

$\sum_{i=1}^{m} y_{i j} \leq 2$

$\sum_{i=1}^{m} z_{i j} \leq 2$

\subsection{Soft Constraint}

Soft constraint (kendala tambahan) adalah batasan yang mempresentasikan peraturan yang dapat dilanggar sewaktu-waktu, namun penyimpangannya diusahakan seminimal mungkin.

a. Kendala 6

Pemenuhan persyaratan agar batas maksimal kebutuhan perawat bekerja disetiap shift kerja terpenuhi untuk setiap $i=1,2, \ldots m$ berlaku:

$\sum_{j=1}^{n} x_{i j} \leq x_{j \max }$ 


$$
\begin{aligned}
& \sum_{j=1}^{m} y_{i j} \leq y_{j \max } \\
& \sum_{j=1}^{n} z_{i j} \leq z_{j \max }
\end{aligned}
$$

b. Kendala 7

Setiap perawat tidak bekerja pada shift malam berturut-turut untuk setiap $i=1,2, \ldots(m-1)$ dan $j=1,2, \ldots, n$ berlaku:

$z_{i j}+z_{(i+1) j} \leq 1$

c. Kendala 8

Total hari kerja yang harus dipenuhi setiap perawat dalam satu periode adalah sebanyak $D_{\text {total }}$. Untuk setiap $i=1,2, \ldots, m$ berlaku:

$$
\sum_{j=1}^{n}\left(x_{i j}+y_{i j}+z_{i j}\right)=D_{\text {total }}
$$

d. Kendala 9

Setiap perawat bekerja paling sedikit shift kerja salam satu periode untuk setiap $j=1,2, \ldots, n$ berlaku:

$$
\begin{aligned}
& \sum_{i=1}^{m} x_{i j} \geq 1 \\
& \sum_{i=1}^{m} y_{i j} \geq 1 \\
& \sum_{i=1}^{m} z_{i j} \geq 1
\end{aligned}
$$

\subsection{Penentuan Bobot Tujuan dan Prioritas}

Berdasarkan data yang diperoleh dari wawancara dengan Kepala Perawat IGD Rumah Sakit Umum Daerah Kota Bandung, maka dalam penelitian ini tidak dilakukan pembobotan dan prioritas pencapaian tujuan dianggap sama. Setiap kebijakan dinilai seimbang dan sama-sama penting. Oleh karena itu dalam penelitian ini pembobotan juga bernilai 1 atau $w_{i}=1$, untuk setiap $i=1,2, \ldots, m$.

\section{$1.5 \quad$ Fungsi Tujuan}

Adapun fungsi tujuan dari penelitian ini adalah untuk meminimumkan penyimpanganpenyimpangan sebagai berikut:

a. Tujuan 1

Meminimumkan penyimpangan pada persamaan (3.14), (3.15), (3.16) yaitu meminimumkan penyimpangan batas maksimal kebutuhan perawat yang bekerja disetiap shift kerja terpenuhi. $d 1_{\mathrm{i}}{ }^{+}$mempresentasikan penyimpangan positif yaitu banyaknya perawat yang bekerja melebihi batas maksimum, sehingga akan ada perawat yang bekerja melebihi batas maksimal banyaknya perawat yang harus terpenuhi (kendala 1). Meminimumkan penyimpanngan positif untuk setiap $i=1,2, \ldots, m$ berlaku: 


$$
\begin{aligned}
& \sum_{j=1}^{n}\left(x_{i j}+d 1_{i}{ }^{+}-d 1_{i}{ }^{-}\right) \leq x_{j \max } \\
& \sum_{j=1}^{m}\left(y_{i j}+d 1_{i}{ }^{+}-d 1_{i}{ }^{-}\right) \leq y_{j \max } \\
& \sum_{j=1}^{n}\left(z_{i j}+d 1_{i}{ }^{+}-d 1_{i}{ }^{-}\right) \leq z_{j \max }
\end{aligned}
$$

b. Tujuan 2

Meminimumkan penyimpangan pada persamaan (3.17) yaitu meminimumkan penyimpanggan adanya perawat yang bekerja pada shift malam dua hari berturut-turut. $d 2_{\mathrm{ij}}{ }^{-}$mempresentasikan penyimpangan positif yang berarti terdapat perawat yang bekerja pada shift malam dua hari berturut-turut atau lebih sehingga dapat mempengaruhi kesehatan perawat. Meminimumkan penyimpangan positif untuk setiap $i=1,2 \ldots(m-1)$ dan $j=1,2, \ldots n$.

$$
z_{i j}+z_{(i+1) j}+d 2_{i j}{ }^{+}-d 2_{i j}{ }^{-} \leq 1
$$

c. Tujuan 3

Meminimumkan penyimpangan pada persamaan (3.18) yaitu meminimumkan penyimpangan pembagian shift yang tidak merata. $d 3_{j}{ }^{+}$merupakan penyimpangan positif yang berarti seorang perawat bekerja lebih dari $D_{\text {total }}$ dalam satu periode dan $d 3_{j}^{-}$ merupakan penyimpangan negatifnya. Meminimumkan penyimpangan positif dan negatif untuk setiap $j=1,2, \ldots, n$

$\sum_{i=1}^{m}\left(x_{i j}+y_{i j}+z_{i j}+d 3_{j}^{+}-d 3_{j}^{-}\right)=D_{\text {total }}$

d. Tujuan 4

Meminimumkan penyimpangan pada persamaan (3.19), (3.20), (3.21) yaitu meminimumkan penyimpangan perawat yang bekerja kurang dari batas minimal masingmasing shift dalam satu periode. $d 4_{j}^{-}$merupakan penyimpangan negatif yang berarti seorang perawat bekerja kurang dari batas minimal mengakibatkan adanya perawat yang tidak bekerja pada suatu shift dalam satu periode untuk setiap $i=1,2, \ldots$, dan $j=1,2, \ldots, n$ berlaku:

$$
\begin{aligned}
& \sum_{j=1}^{n}\left(x_{i j}+d 4_{i}{ }^{+}-d 4_{i}{ }^{-}\right) \geq 1 \\
& \sum_{j=1}^{m}\left(y_{i j}+d 4_{j}{ }^{-}+d 4_{j}{ }^{+}\right) \geq 1 \\
& \sum_{j=1}^{m}\left(x_{i j}+d 4_{j}^{-}+d 4_{j}{ }^{+}\right) \geq 1
\end{aligned}
$$

\section{Studi Kasus}

Dalam penjadwalan perawat IGD di Rumah Sakit Umum Daerah Kota Bandung mengambil kebijakan untuk membagi jam kerja perawat menjadi tiga shift, yaitu shift pagi pada pukul 07.3014.30, shift siang pada pukul 14.30-21.30, dan shift malam pukul 21.30-07.30. setiap perawat 
bertugas selama lima hari dalam satu beriode (satu minggu). Jumlah perawat IGD di Rumah Sakit Umum Daerah Kota Bandung adalah 24 perawat.

Indek yang digunakan dalam studi kasus ini adalah sebagai berikut:

$i$ :indeks untuk hari, $i=1,2, \ldots 7$

$j$ : indeks untuk perawat, $i=1,2, \ldots 24$

Untuk data penelitian yang digunakan dalam studi kasus ini disajikan pada Tabel 2.

\begin{tabular}{ll}
\multicolumn{2}{l}{ Tabel 2. Data Penelitian pada Studi Kasus } \\
\hline Parameter \\
\hline$m$ & 7 hari \\
$n$ & 24 perawat \\
$x_{\text {jmax }}$ & 6 perawat \\
$x_{\text {jmin }}$ & 5 perawat \\
$y_{\text {jmax }}$ & 6 perawat \\
$y_{\text {jmin }}$ & 5 perawat \\
$z_{\text {jmax }}$ & 6 perawat \\
$z_{\text {jmin }}$ & 5 perawat \\
$D_{\text {total }}$ & 5 hari \\
\hline
\end{tabular}

Sehingga model Goal Programming untuk masalah penjadwalan perawat IGD di Rumah Sakit Umum Kota Bandung adalah sebagai berikut:

$\operatorname{Min}\left(\sum_{i}\left(d 1_{i}^{+}\right)+\sum_{j}\left(d 2_{j}^{+}\right)+\sum_{i} \sum_{j}\left(d 3_{i j}{ }^{+}+d 3_{i j}{ }^{-}\right)+\sum_{j}\left(d 4_{j}^{-}\right)\right)$

dengan kendala :

$\sum_{j=1}^{24} x_{i j} \geq 5$ untuk $i=1,2, \ldots, 7$

$\sum_{j=1}^{24} y_{i j} \geq 5$ untuk $i=1,2, \ldots 7$

$\sum_{j=1}^{24} z_{i j} \geq 5$ untuk $i=1,2, \ldots 7$

$\sum_{j=1}^{n}\left(x_{i j}+y_{i j}+z_{i j}+h_{i j}\right)=24$ untuk $i=1,2, \ldots 7$

$x_{i j}+y_{i j}+z_{i j}+h_{i j}=1 i=1,2, \ldots, 7$ dan $j=1,2, \ldots, 24$

$z_{\mathrm{ij} j}+x_{(i+1) j}+y_{(i+1) j}+z_{(i+1) j} \leq 1$

untuk $i=1,2, \ldots, 6$ dan $j=1,2, \ldots, 24$

$\sum_{\mathrm{i}=1}^{7} x_{i j} \leq 2$ untuk $i=1,2, \ldots, 7$

$\sum_{\mathrm{i}=1}^{7} y_{i j} \leq 2$ untuk $i=1,2, \ldots 7$

$\sum_{\mathrm{i}=1}^{7} z_{\mathrm{i} j} \leq 2$ untuk $i=1,2, \ldots 7$

$\sum_{j=1}^{7} x_{i j}+d 1_{i j}{ }^{-}+d 1_{i j}{ }^{+} \leq 6$ untuk $i=1,2, \ldots 7$ 
$\sum_{j=1}^{24} y_{i j}+d 1_{i j}{ }^{-}+d 1_{i j}{ }^{+} \leq 6$ untuk $i=1,2, \ldots 7$

$\sum_{j=1}^{24} z_{i j}+d 1_{i j}{ }^{-}+d 1_{i j}{ }^{+} \leq 6$ untuk $i=1,2, \ldots 7$

$z_{i j}+z_{(i+1) j}+d 2_{i j}{ }^{-}+d 2_{i j}{ }^{+} \leq 1$

untuk $i=1,2, \ldots, 6$ dan $j=1,2, \ldots, 24$

$\sum_{i=1}^{7}\left(x_{i j}+y_{i j}+z_{i j}+d 3_{j}^{-}+d 3_{j}^{+}\right)=5$ untuk $j=1,2, \ldots, 24$

$\sum_{\mathrm{i}=1}^{7} x_{\mathrm{ij}}+d 1_{\mathrm{ij}}{ }^{-}+d 1_{\mathrm{ij}}{ }^{+} \geq 1$ untuk $j=1,2, \ldots, 24$

$\sum_{\mathrm{i}=1}^{7} y_{\mathrm{ij}}+d 1_{\mathrm{ij}}{ }^{-}+d 1_{\mathrm{ij}}{ }^{+} \geq 1$ untuk $j=1,2, \ldots, 24$

$\sum_{i=1}^{7} z_{i j}+d 1_{i j}{ }^{-}+d 1_{i j}{ }^{+} \geq 1$ untuk $j=1,2, \ldots 24$

$x=0$ atau $1 ; y=0$ atau $1 ; z=0$ atau 1

$d 1_{i}{ }^{+}, d 1_{i}{ }^{-}, d 2_{i j}{ }^{+}, d 2_{i j}{ }^{-}, d 3_{j}{ }^{+}, d 3_{j}{ }^{-}, d 4_{j}{ }^{+}, d 4_{j}{ }^{-} \geq 0$

\section{Hasil dan Pembahasan}

Untuk menyelesaikan model di atas digunakan aplikasi Maple 18. Dari perhitungan menggunakan maple diperoleh nilai minimal yang didapat yaitu 0 , yang artinya setiap tujuan tercapai dengan tidak terdapat penyimpangan pada masing-masing tujuan. Oleh karena itu, solusi merupakan solusi yang optimal dari permasalahan penjadwalan perawat di Rumah Sakit Umum Daerah Kota Bandung.

Kemudian Hasil dari Maple ini diterjemahkan menjadi bentuk jadwal kerja perawat yang disajikan pada Tabel 3.

Tabel 3. Jadwal Perawat Berdasarkan Perhitungan Maple18

\begin{tabular}{|c|c|c|c|c|c|c|c|c|}
\hline \multirow{2}{*}{ Perawat } & \multicolumn{7}{|c|}{ Hari } & \multirow{2}{*}{$\mathrm{J}$} \\
\hline & 1 & 2 & 3 & 4 & 5 & 6 & 7 & \\
\hline 1 & $S$ & $M$ & $\mathrm{~L}$ & $P$ & $S$ & $M$ & $\mathrm{~L}$ & 41 \\
\hline 2 & $P$ & $S$ & $P$ & $M$ & $\mathrm{~L}$ & M & $L$ & 41 \\
\hline 3 & $S$ & $S$ & $P$ & M & $\mathrm{L}$ & $P$ & $L$ & 38 \\
\hline 4 & $\mathrm{~L}$ & $S$ & $M$ & L & $S$ & $P$ & $M$ & 48 \\
\hline 5 & $S$ & $P$ & $S$ & $P$ & $M$ & L & $\mathrm{L}$ & 38 \\
\hline 6 & $S$ & $P$ & $S$ & M & $\mathrm{L}$ & M & $L$ & 41 \\
\hline 7 & $\mathrm{M}$ & $L$ & $S$ & $S$ & $\mathrm{M}$ & L & $P$ & 41 \\
\hline 8 & $S$ & $S$ & $M$ & L & $P$ & M & $L$ & 41 \\
\hline 9 & $\mathrm{~L}$ & $S$ & $S$ & $P$ & $\mathrm{M}$ & L & M & 41 \\
\hline 10 & $M$ & $\mathrm{~L}$ & $S$ & $P$ & $S$ & $P$ & L & 38 \\
\hline 11 & $P$ & $S$ & $P$ & M & $\mathrm{L}$ & $S$ & L & 38 \\
\hline 12 & $P$ & $P$ & $M$ & L & $S$ & M & L & 41 \\
\hline 13 & $S$ & $M$ & $L$ & $P$ & $M$ & $L$ & $S$ & 41 \\
\hline 14 & $P$ & $P$ & $S$ & M & $L$ & $L$ & $S$ & 38 \\
\hline 15 & $P$ & $M$ & $L$ & $S$ & $M$ & $L$ & $P$ & 41 \\
\hline 16 & $M$ & $L$ & $P$ & M & $L$ & $S$ & $P$ & 41 \\
\hline 17 & $\mathrm{M}$ & $L$ & $P$ & $S$ & $S$ & L & $P$ & 38 \\
\hline 18 & $M$ & $L$ & $\mathrm{M}$ & $\mathrm{L}$ & $P$ & $P$ & $S$ & 41 \\
\hline
\end{tabular}




\begin{tabular}{ccccccccc}
19 & $\mathrm{~L}$ & $\mathrm{M}$ & $\mathrm{L}$ & $\mathrm{S}$ & $\mathrm{P}$ & $\mathrm{P}$ & $\mathrm{M}$ & 41 \\
20 & $\mathrm{~L}$ & $\mathrm{P}$ & $\mathrm{M}$ & $\mathrm{L}$ & $\mathrm{P}$ & $\mathrm{S}$ & $\mathrm{S}$ & 38 \\
21 & $\mathrm{~L}$ & $\mathrm{M}$ & $\mathrm{L}$ & $\mathrm{S}$ & $\mathrm{P}$ & $\mathrm{S}$ & $\mathrm{M}$ & 41 \\
22 & $\mathrm{M}$ & $\mathrm{L}$ & $\mathrm{P}$ & $\mathrm{P}$ & $\mathrm{M}$ & $\mathrm{L}$ & $\mathrm{S}$ & 41 \\
23 & $\mathrm{~L}$ & $\mathrm{P}$ & $\mathrm{M}$ & $\mathrm{L}$ & $\mathrm{P}$ & $\mathrm{S}$ & $\mathrm{M}$ & 41 \\
24 & $\mathrm{~L}$ & $\mathrm{M}$ & $\mathrm{L}$ & $\mathrm{S}$ & $\mathrm{S}$ & $\mathrm{P}$ & $\mathrm{P}$ & 38 \\
\hline Jumlah perawat P & 5 & 6 & 6 & 6 & 6 & 6 & 5 & \\
\hline Jumlah perawat S & 6 & 6 & 6 & 6 & 5 & 5 & 5 & \\
\hline Jumlah perawat M & 6 & 6 & 6 & 6 & 6 & 5 & 5 & \\
\hline Jumlah perawat L & 7 & 6 & 6 & 6 & 7 & 8 & 9 & \\
\hline
\end{tabular}

Keterangan:

$P$ : shift pagi

$S$ : shift siang

$M$ : shift malam

$\mathrm{L}:$ libur

$\mathrm{J}$ : jumlah jam kerja perawat dalam tujuh hari

Dari Tabel 3 maka diperoleh:

1. Batas minimal perawat terpenuhi.

2. Jumlah perawat yang bekerja pada shift pagi, shift siang, shift malam dan perawat yang tidak bekerja dalam satu hari berjumlah 24 perawat terpenuhi.

3. Kebijakan bahwa setiap perawat bekerja pada satu shift dalam satu hari terpenuhi.

4. $\quad$ Perawat yang bekerja pada shift malam, maka pada hari berikutnya libur terpenuhi.

5. Kebutuhan maksimal perawat bekerja pada setiap shift dalam satu periode waktu terpenuhi.

6. Batas maksimal kebutuhan perawat tidak terlampaui.

7. Tidak ada perawat yang bekerja pada shift malam secara berturut-turut.

8. Setiap perawat bekerja selama lima hari dalam satu periode.

9. Batas minimal perawat bekerja pada setiap shift dalam satu periode waktu tidak terlampaui.

\section{KESIMPULAN}

Metode Goal Programming dapat diterapkan pada penjadwalan perawat IGD Rumah Sakit Umum Kota Bandung dengan menentukan variabel-variabel keputusan, menentukan fungsi tujuan berdasarkan data yang didapat, menentukan fungsi kendala berdasarkan data yang didapat, dan diperoleh model yang dapat dilihat pada persamaan bagian hasil dan pembahasan yaitu persamaan 3.30 sampai 3.47. Hasil penjadwalan menggunakan Metode Goal Programming pada perawat IGD Rumah Sakit Umum Kota Bandung menunjukkan tidak ada penyimpangan yang terjadi pada setiap kendala. Penjadwalan perawat dengan menggunakan Metode Goal Programming dan alat bantu aplikasi Maple18 dapat dilihat pada Tabel 3.

\section{REKOMENDASI}

Penelitian ini menggunakan periode waktu tujuh hari maka jadwal perawat setiap minggunya tidak bervariasi. Oleh sebab itu, rekomendasi untuk penelitian selanjutnya dapat membuat penjadwalan perawat untuk periode waktu satu bulan atau lebih. Aplikasi yang digunakan untuk menyelesaikan penjadwalan menggunakan Metode Goal Programming agar mendapat hasi yang optimal yaitu aplikasi Maple18. Untuk penelitian selanjutnya, diharapkan menyelesaikan permasalahan Goal Programming menggunakan aplikasi selain Maple, misalnya LINGO.

\section{UCAPAN TERIMAKASIH}

Penulis mengucapkan terimakasih kepada Eman Lesmana, Drs., MSIE. dan Julita Nahar, Dra., MT. karena dukungan dan bimbingannya dalam menyelesaikan penelitian ini. 


\section{DAFTAR PUSTAKA}

Elomri, A., Elthlatiny, S., \& Mohamed, Z.S. (2015). A Goal Programming Model for Fairy Scheduling Medicine Racidents. International Journal of Supply Chain Management, 4(2).

Hakim, L., Bakhtiar, T., \& Jaharuddin. (2018). Model Goal Programming dan Pengoptimuman Taklinear pada Penjadwalan Perawat. Jurnal Matematika dan Aplikasinya, 15(1), $23-32$.

Hiller, F.S., \& Lieberman, G.J., (2001). Introduction to Operations Risearch. California. United States of America.

Husen, A. (2008). Manajemen Proyek, Perencanaan, Penjadwalan dan Pengendalian Proyek. Yogyakarta.

Jaenal, R., Ismail, W.R, Yeun, L.C \& Oughalime, A. (2011). A Cyclical Nurse Schedule Using Goal Programming. Lembaga Penelitian dan Pengabdian Kepada Masyarakat ITB, 43 A(3), 151164.

Siregar. P., Gamal. M.D.H. \& Saleh. H. (2015). Optimisasi Penjadwalan dengan Goal Programming: Sebuah Studi Kasus Rumah Sakit Umum Padangsidimpuan. Prosiding Semirata2015 bidang MIPA BKS-PTN Barat, Universitas Riau. 385-395.

Taha, H.A. (1997). Sixth Edition Operations Research an Introduction. United States of America. 
-110 Teorema: Teori dan Riset Matematika, 4(2), 99-110, September 2019 